\title{
Iodine Malnutrition and Associated Factors in Schoolchildren Aged 6 to 14 Years in a Municipality Situated in the Semi-Arid Region of the State of Minas Gerais, Brazil, 2008
}

\author{
Mariana de Souza Macedo', Romero Alves Teixeira², Élido Bonomo³, \\ Camilo Adalton Mariano da Silva ${ }^{3}$, Mariângela Carneiro ${ }^{4}$, Marcelo Eustáquio Silva ${ }^{3}$, \\ Emília Sakurai ${ }^{5}$, Joel Alves Lamounier ${ }^{6}$ \\ ${ }^{1}$ Graduate Center, School of Medicine, Federal University of Minas Gerais, Belo Horizonte, Brazil \\ ${ }^{2}$ Department of Nutrition, School of Biological and Health Sciences, Federal University of the Jequitinhonha and \\ Mucuri, Diamantina, Brazil \\ ${ }^{3}$ School of Nutrition, Federal University of Ouro Preto, Ouro Preto, Brazil \\ ${ }^{4}$ Institute of Biological Sciences, Federal University of Minas Gerais, Belo Horizonte, Brazil \\ ${ }^{5}$ Institute of Mathematical Sciences, Federal University of Minas Gerais, Belo Horizonte, Brazil \\ ${ }^{6}$ Department of Pediatrics, School of Medicine, Federal University of São João Del Rei, Divinópolis, Brazil \\ Email: marysmacedo@yahoo.com.br
}

Received 29 August 2014; revised 30 September 2014; accepted 12 October 2014

Copyright (C) 2014 by authors and Scientific Research Publishing Inc.

This work is licensed under the Creative Commons Attribution International License (CC BY).

http://creativecommons.org/licenses/by/4.0/

(c) (i) Open Access

\section{Abstract}

The objective of this study was to assess the prevalence of iodine deficiency and possible correlated factors among schoolchildren in the municipality of Novo Cruzeiro-MG by means of an evaluation of urinary iodine excretion. Five hundred and forty schoolchildren aged 6 to 14 years selected by stratified sampling, were evaluated. Urine samples were analyzed using the SandellKolthoff method preconized by the WHO and iodine concentrations in the salt were assessed by means of volumetric analysis, in accordance with recommendations from the Ministry of Health. Iodine deficiency was observed in $38.9 \%$ of the schoolchildren. Of these, $28.7 \%$ of them presented slight deficiency, $6.2 \%$ of them were moderately deficient and $4 \%$ of them were seriously deficient. Median urinary iodine levels in the urban and rural population were 150.8 and $119.2 \mu \mathrm{g} / \mathrm{L}$, respectively, with a clear distribution of iodine deficiency among the populations $(p<0.001)$ being registered. It was also observed that there was a high prevalence of deficient urinary iodine excretion among schoolchildren that consumed salt with an insufficient iodine content. In relation to 
the quality of the salt consumed by families, in $12.2 \%$ of the residences studied the iodine content in salt was below the recommended level $(20 \mathrm{mg} / \mathrm{kg})$, while the iodine content was below 15 $\mathrm{mg} / \mathrm{kg}$ in only $5.3 \%$ of them. The results indicated that, although not characterized as a public health issue, according to WHO criteria, iodine deficiency showed very high prevalence among schoolchildren in this region. Regarding the iodine content of salt found in household consumption, our findings indicated the National Program of Salt Iodination was not efficient in the city, since it did not hit the target proposed by the Ministry of Health. Furthermore, low urinary iodine excretion associated with the consumption of salt with low iodine content suggests the need for periodical evaluations in order to provide effective control of the endemic disease.

\section{Keywords}

Iodine Status, Iodine Deficiency, Urinary Iodine, Iodized Salt, Schoolchildren

\section{Introduction}

Iodine is a microelement essential for the proper functioning of the thyroid gland, as its main function in the body is the synthesis of the following thyroid hormones: triiodothyronine $\left(\mathrm{T}_{3}\right)$ and thyroxine $\left(\mathrm{T}_{4}\right)$. Individual needs and, consequently, the daily recommended intake of iodine vary in function of age and the physiological cycle. The daily recommended intake has been established at $50 \mu \mathrm{g} /$ day for breastfeeding infants of one to 12 months of age, $90 \mu \mathrm{g} /$ day for children aged two to six, $120 \mu \mathrm{g}$ /day for children aged seven to twelve, $150 \mu \mathrm{g} / \mathrm{day}$ for adolescents and adults and $200 \mu \mathrm{g} /$ day for pregnant women and breastfeeding mothers [1].

When daily dietary iodine requirement is not met, a chain of functional alterations called iodine deficiency disorders (IDD) begins.

Currently, the term IDD not only refers to extreme situations associated with chronic iodine deficiency, such as goiter or endemic cretinism, but also encompasses a broad spectrum of alterations resulting from this form of malnutrition, the effects of which on human growth and development result in the appearance of manifestations that are subtle, yet more damaging from a clinical point of view.

Such manifestations include, among schoolchildren, subclinical hypothyroidism, a reduction in linear growth, a reduction in sexual maturity among girls and, especially, mental retardation and retardation of cognitive development with a deficit in the ability to learn and an increase in school failure and truancy rates. However, such manifestations tend to be underestimated and poorly assessed in situations of slight or moderate deficiency [2].

With the recognition of the potentially harmful and irreversible effects of iodine deficiency, even to a small degree, on cerebral development as well as the socio-economic impact associated with a reduction in intellectual and productive capacity, this nutritional deficiency has come to represent one of the main obstacles to good health among children and to the development of resident populations in areas with iodine insufficiency [3].

In this context, the WHO, mandated the universal addition of iodine to salt as prioritized strategy in the effort to combat and control disorders resulting from iodine deficiency [4].

In Brazil, national studies have indicated a trend towards a fall in the prevalence of goiter among schoolchildren.

The first study, conducted in 1955, found a $20.7 \%$ prevalence of goiter among schoolchildren and marked out the endemic areas. Twenty years later, the second national study reported a prevalence of goiter of $14.1 \%$, representing a reduction of only $6.5 \%$ in that period, but with a significant reduction in visible goiters [5].

Between 1994 and 1996, the third national study into endemic goiter prevalence, complemented by an analysis of urinary iodine excretion, revealed as prevalence for goiter of $4 \%$ and reached the conclusion that $76 \%$ of Brazilian municipalities did not present signs of iodine deficiency [6]. On the other hand, regarding urinary iodine excretion, the proportion of schoolchildren living in situations of iodine deficiency was shown to be quite significant (32.91\%) [6].

In 2000, the Thyromobil project was conducted in Brazil. This project identified a prevalence of goiter of $1.4 \%$. An analysis of urinary iodine revealed median values that were considered high in all the municipalities surveyed, at levels around $360 \mu \mathrm{g} / \mathrm{L}$, indicating excessive iodine ingestions at that time [7].

The significant reduction in goiter rates recorded in the last 50 years highlights the considerable advances 
made in controlling the endemic goiter resulting from iodine deficiency in Brazil. However, in depth studies demonstrated greater iodine deficiency among school children in the area of Ouro Preto with a prevalence of $67.5 \%$, with an association between deficient urinary excretion and insufficient iodine content in salt [8].

Considering the heterogeneity of the distribution of endemic iodine deficiency, it is clear that there is a need for periodical monitoring as a means of subsidizing control and prevention measures aimed at the disorders resulting from iodine deficiency currently found in Brazil. In addition, regarding monitoring of iodine nutrition throughout the population, the WHO recommends the evaluation of school age children, due to easy access and their greater vulnerability to the adverse effects of iodine deficiency that are characteristic of this age group [9] [10].

In this context, the object of this work is to evaluate the prevalence of iodine deficiency among schoolchildren in Novo Cruzeiro, by means of an analysis of urinary iodine, and to identify the possible factors associated with this.

\section{Methodology}

This study is an integral part of an original project titled "Nutritional profile and food consumption among preschoolers and schoolchildren in two municipalities in the Jequitinhonha and Mucuri valleys in the semi-arid region of Minas Gerais". This project proposes to evaluate various nutritional disorders such Deficiency of vitamin A, iron and zinc in addition to the assessment of dietary intake, nutritional status and situation of food and nutritional security among schoolchildren.

The study was conducted in the municipality of Novo Cruzeiro during the period between February 15 and March 15 of 2008 and included 540 children and adolescents between 6 and 14 years of age, their families and residences.

This is a transversal, descriptive study of the population base, conducted through interviews held in residences with the probabilistic sampling model selected by a stratified two-stage sampling.

The sample was calculated taking into consideration an expected prevalence of $50 \%$ so as to guarantee the representativeness of all the events planned in the original project mentioned above, an acceptable margin of error of $5 \%$ and a confidence interval of $95 \%$, with a total of 341 schoolchildren.

In the first stage, a draw was held, using simple random sampling, to select the microareas registered with the Family Health Strategy (ESF) that were to be visited, thereby guaranteeing the representativeness of both the rural and urban environments. In the second stage, in each microarea a draw was held to select the residences to be investigated. After all the data had been collected and processed, the final sample to be analyzed included 540 children, which was a greater number than had been intended for the sample.

Chosen for the study were all the schoolchildren belonging to the established age group that were residents of the municipality of Novo Cruzeiro at the time and whose parents or guardians authorized their participation in the study. On the other hand, those children that had recently taken mineral supplements or medication that could interfere with the absorption and/or metabolism of dietary iodine or that were not given authorization by their parents were excluded.

In order to characterize the population, socio-economic, demographic, environmental and health information were collected on each child studied by means of a semi-structured questionnaire that had been previously validated in a prior study [11]. Information was also collected regarding the storage and consumption conditions for iodized salt in the residential environment, as well as the food and nutritional security of the families investigated.

During the interview, approximately 20 - 30 grams of the table salt being used in food preparation at the household was collected. In an air tight container for latter chemical iodine assessment.

The measurement of the iodine content of the salt was conducted in accordance with the technique recommended by the Ministry of Health, in which, using potassium iodide (KI) and, in an acid environment, potassium iodate $\left(\mathrm{KIO}_{3}\right)$, which is a substance utilized in the salt iodization process, reacts releasing iodine, which is called sodium thiosulfate, utilizing a starch solution as an indicator.

The classification of the salt samples in terms of the concentration of iodine found was based on the limits established by RDC Resolution No. 130, of May $16^{\text {th }}$, 2003, with values of between 20 and $60 \mathrm{mg}$ of iodine per kilogram of salt being considered adequate [12].

The parents were provided with acid washed glass tubes and were given instructions to collect morning urine samples from their children.

The analysis of the urinary iodine was performed at the Bromatology Laboratory at the School of Nutrition at 
the Federal University of Ouro Preto in a double blind manner, with no previous knowledge of the origin or diagnostic regarding the salt sample from the corresponding residence.

The urinary iodine was determined using the Sandell-Kolthoff method [13] [14]. The method is based on the catalytic role of iodine in the reduction of cerium ion to the cerous ion coupled with the oxidation of arsenite [15]. The intensity of the yellow color was measured spectrophotometrically.

The classification of the iodine nutritional status of the schoolchildren evaluated followed the international epidemiological criteria presented in the Table 1.

Statistical analysis, an investigation was conducted into the possible associations between the independent variables and iodine deficiency by means of the application of Pearson's chi-square test at a significance level of $\alpha$ $=0.2$. For this purpose, the variables were organized and analyzed in a hierarchical manner in four large blocks: variables related to the consumption and storage of salt, biological and health-related variables, environmental and socio-economic variables.

Regarding the continuous variables, the Krushkal-Wallis test was applied for the comparison of the median values for urinary iodine and the iodine content in the salt among the urban and rural populations, with a significance level of $\alpha=0.05$ being adopted.

Following the pre-selection of the variables of interest, a logistic regression model was constructed in order to evaluate the independent effect of each variant on the behavior of iodine deficiency. The stepwise backward method and the Wald statistical test were applied, with a p value of $>0.005$ being adopted as the exclusion factor for the model. In this stage of the analysis of the variables that did not significantly modify the odds ratio values and respective confidence intervals were successively discarded from the initial model. Later, we proceeded with the evaluation and control of the possible confusion effects.

The database was constructed using the version 6.04 of the Epiinfo program and the analysis was performed with the assistance of the Statistical Package for the Social Sciences (SPSS), version 13.0.

This study was submitted to the Research Ethics Committee of the Federal University of Minas Gerais and was approved, in accordance with the regulations established in Resolution No. 196/96 of the National Health Council based on opinion No. ETIC 0184/06. In addition, all the schoolchildren evaluated delivered an informed consent form duly understood and signed by their parents or guardians, in triplicate.

\section{Results}

An analysis was conducted of 339 samples of table salt being used in food preparation in the residences of the schoolchildren participating in the study, among which $12 \%$ were observed to have values below $20 \mathrm{mg}$ of iodine per kilogram of salt, indicating an unsatisfactory quantity of iodine in the salt being consumed. Of these, $5.8 \%$ presented an iodine concentration of less than $15 \mathrm{mg} / \mathrm{kg}$.

On the other hand, $85.5 \%$ were considered adequate and $2.3 \%$ presented an iodine content above the maximum limit of $60 \mathrm{mg} / \mathrm{kg}$ established in the respective legislation.

Regarding the median concentrations of iodine in the salt, both the urban and rural populations presented values in excess of $20 \mathrm{mg} / \mathrm{kg}$, which is the minimum limit established to qualify as an adequate supply of iodine delivered through table salt. The values found were 28.9 and $30 \mathrm{mg}$ of iodine/ $\mathrm{kg}$ of slat in the urban and rural environment, respectively, with no significant difference being noted according to the Kruskal-Wallis test ( $p>0.05)$.

Table 1. Epidemiological criteria for the classification of the iodine nutritional status according to the median concentration of urinary iodine [16].

\begin{tabular}{ccc}
\hline Median value $(\mathbf{m g} / \mathbf{L})$ & Iodine ingestion & Iodine nutrition \\
\hline$<20$ & Insufficient & Severe iodine deficiency \\
$20-49$ & Insufficient & Moderate iodine deficiency \\
$50-99$ & Insufficient & Slight iodine deficiency \\
$100-199$ & Adequate & Excellent \\
$200-299$ & More than adequate & Risk of iodine-induced hyperthyroidism \\
$>300$ & Excessive & Risk of adverse effects (iodine-induced hyperthyroidism and \\
chronic autoimmune thyroiditis)
\end{tabular}

Source: WHO, 2004. 
As for the variables related to the storage and consumption of iodized salt, the incorrect storage of iodized salt, a lack of attention to the pertinent information on the packaging labels of table salt and the low level of maternal instruction were associated in a significant manner with the iodine content present in the table salt $(p>0.001)$, as can be seen in Table 2 .

\section{Analysis of Urinary Iodine}

The prevalence of urinary iodine deficiency among schoolchildren in Novo Cruzeiro was $38.9 \%$. Of these, $28.7 \%$ presented a slight deficiency (urinary iodine $<100 \mu \mathrm{g} / \mathrm{L}$ ), $6.2 \%$ presented moderate deficiency (urinary iodine $<50 \mu \mathrm{g} / \mathrm{L}$ ) and $4 \%$ presented severe deficiency (urinary iodine $<20 \mu \mathrm{g} / \mathrm{L}$ ).

The distribution of iodine deficiency was presented in a distinct manner, according to the location of the residence ( $\mathrm{p}<0.001$ ), with the proportion of schoolchildren presenting iodine deficiency being higher in the rural environment when compared with the urban environment. Also, among the rural population, the incidence of moderate to severe deficiency was almost three times more frequent Table 3.

Regarding the median urinary iodine values, the values found among the urban population was $152 \mu \mathrm{g} / \mathrm{L}$, with the interquartile interval varying between 100.8 and $165.8 \mu \mathrm{g} / \mathrm{L}$. In the rural environment, the median excretion of urinary iodine was $112 \mu \mathrm{g} / \mathrm{L}$, with an interquartile interval of between 74.3 and $140 \mu \mathrm{g} / \mathrm{L}$.

Though the median concentrations of urinary iodine presented, both in the urban and rural environments, values superior to $100 \mu \mathrm{g} / \mathrm{L}$, which is the minimum limit preconized as being indicative of adequate recent nutria-

Table 2. Variables related to the storage and consumption of iodized salt associated with the iodine content of salt consumed by the families of schoolchildren, Novo Cruzeiro, 2008.

\begin{tabular}{|c|c|c|c|c|}
\hline \multirow{2}{*}{ Variables } & \multicolumn{2}{|c|}{ Iodine content in the salt } & \multirow{2}{*}{ p value } & \multirow{2}{*}{ OR (CI 95\%) } \\
\hline & Insufficient & Adequate & & \\
\hline \multicolumn{5}{|l|}{ Salt storage method } \\
\hline Incorrect & 15.1 & 84.9 & $<0.001$ & 13.4 \\
\hline Correct & 1.3 & 98.7 & & $(6.3-28.3)$ \\
\hline \multicolumn{5}{|c|}{ Information on the salt package labels } \\
\hline Complies & 11.1 & 88.9 & $<0.001$ & 1.56 \\
\hline Does not comply & 16.2 & 83.8 & & $(1.32-1.84)$ \\
\hline \multicolumn{5}{|c|}{ Mothers' level of education } \\
\hline Up to 4 years & 32.7 & 67.3 & $<0.001$ & 3.44 \\
\hline More than 4 years & 12.4 & 87.6 & & $(2.8-4.22)$ \\
\hline
\end{tabular}

*The reference category is presented in the second line.

Table 3. Distribution of the concentration of urinary iodine among schoolchildren residing in the urban and rural environments, Novo Cruzeiro, 2008.

\begin{tabular}{|c|c|c|c|c|c|c|}
\hline \multirow{2}{*}{$\begin{array}{l}\text { Urinary iodine content } \\
(\mu \mathrm{g} / \mathrm{L})\end{array}$} & \multicolumn{2}{|c|}{ Urban } & \multicolumn{2}{|c|}{ Rural } & \multicolumn{2}{|c|}{ Total } \\
\hline & $\mathrm{N}$ & $\%$ & $\mathrm{~N}$ & $\%$ & $\mathrm{~N}$ & $\%$ \\
\hline$\geq 100$ (adequate) & 82 & 77.6 & 241 & 56 & 323 & 61.1 \\
\hline 50 - 99 (slight deficiency) & 20 & 17.8 & 132 & 32 & 152 & 28.7 \\
\hline 20 - 49 (moderate deficiency) & 4 & 2.9 & 36 & 7.2 & 40 & 6.2 \\
\hline <20 (severe deficiency) & 1 & 1.6 & 24 & 4.8 & 25 & 4.0 \\
\hline Total & 107 & 100 & 433 & 100 & 540 & 100 \\
\hline
\end{tabular}

$\mathrm{N}$ : Number of samples. 
tional ingestion of iodine, the Kruskal-Wallis test showed that there was a significant difference between them $(\mathrm{p}<0.001)$. Also, considering the interquartile interval, a borderline distribution of urinary iodine excretion was observed among schoolchildren residing in the rural environment.

In relation to the concentration of iodine in table salt, a higher prevalence of marginal urinary iodine deficiency was detected among the population whose iodine consumption of iodine by table salt was considered insufficient, in which cases of moderate and severe deficiency were two times more prevalent $(\mathrm{p}<0.001)$ Table 4.

Based on an exploratory bivariate analysis conducted hierarchically in blocks, candidate variables were selected to compose the final logistic model utilizing a significance level of 0.2 .

Table 5 presents the hierarchical blocks with the variables related to the storage and consumption of iodized salt and the biological, health-related, socio-economic and environmental variables that were shown to be associated with iodine deficiency in this stage of the analysis and their respective $\mathrm{p}$ values.

Based on the variables that were pre-selected in the bivariate stage, a logistic model was constructed which contains the adjusted values for the odds ratio, a confidence interval of 95\%, the effect coefficient, the Wald statistic and the p value.

As can be seen in Table 6, the variables associated with the excretion of urinary iodine that best explain the distribution of iodine deficiency among schoolchildren in Novo Cruzeiro were: iodized salt concept, iodine content in the salt, age group, location of the residence, mother's level of schooling and food and nutritional security.

\section{Discussion}

The addition of iodine to salt has been preconized as the main action strategy in the effort to eliminate and prevent endemic iodine deficiency, with this strategy being used for decades in many developed countries where diseases resulting from this form of malnutrition have since been brought under control and considerable progress has been made with regards to the universal addition of iodine to salt [17]. This intervention strategy is normally prioritized in the fight against disorders due to iodine deficiency, in function of the regular consumption of salt by the population [18]. Indeed, the iodine deficiency prevention and control programs must guarantee the adequate addition of iodine to table salt, whether imported or produced domestically [17], so as to ensure the provision of sufficient quantities of iodine throughout the country. In this sense, the periodical monitoring of the concentrations of iodine in salt available for consumption is preconized by the WHO as a fundamental parameter for the evaluation of the dietetic intake of iodine and must always be associated with the excretion of urinary iodine.

This study found that $12.2 \%$ of the residences studied presented an iodine concentration in salt below the minimum adequacy limit established in the current legislation in country $(20 \mathrm{mg} / \mathrm{kg})$. Of these, $5.3 \%$ exhibited values below $15 \mathrm{mg} / \mathrm{kg}$. In accordance with the international criteria proposed by the WHO, which recommends a minimum concentration of $15 \mathrm{mg}$ of iodine per kilogram of salt in at least $90 \%$ of residences, the results of the study highlight the effective coverage of the iodine addition program in the municipality.

Table 4. Distribution of urinary iodine concentration among schoolchildren according to the iodine concentration in table salt, Novo Cruzeiro, 2008.

\begin{tabular}{ccccc}
\hline & \multicolumn{4}{c}{ Iodine in salt (mg/kg) } \\
\cline { 2 - 5 } Urinary iodine $(\boldsymbol{\mu g} / \mathbf{L})$ & $\mathbf{N}$ & $\mathbf{\%}$ & $\mathbf{N}$ & $\mathbf{\%}$ \\
\cline { 2 - 5 } & 36 & 57.4 & 261 & 61.3 \\
\hline 100 (adequate) & 17 & 23.2 & 124 & 29.5 \\
$50-99$ (slight deficiency) & 9 & 11 & 28 & 5.8 \\
$20-49$ (moderate deficiency) & 6 & 8.3 & 18 & 3.4 \\
$<20$ (severe deficiency) & 68 & 100 & 431 & 100 \\
\hline
\end{tabular}

N: Number of samples. 
Table 5. Variables related to the storage and consumption of iodized salt associated with iodine deficiency in schoolchildren, Novo Cruzeiro, 2008.

\begin{tabular}{|c|c|c|c|}
\hline \multirow{2}{*}{ Variables } & \multicolumn{3}{|c|}{ Iodine nutritional status } \\
\hline & Deficient (\%) & No deficiency (\%) & p value* \\
\hline \multicolumn{4}{|l|}{ Salt storage and consumption variables } \\
\hline \multicolumn{4}{|l|}{ Concept of iodized salt } \\
\hline No & 41.4 & 58.6 & $<0.001$ \\
\hline \multicolumn{4}{|l|}{ Information on the salt package label } \\
\hline Not observed & 43.2 & 56.8 & $<0.001$ \\
\hline \multicolumn{4}{|c|}{$\begin{array}{l}\text { Received information on iodized salt from PACS } \\
\text { (the Community Healthcare Agents Program) }\end{array}$} \\
\hline No & 39.8 & 60.2 & 0.002 \\
\hline \multicolumn{4}{|l|}{ Use of homemade salt-based seasoning } \\
\hline Yes & 39.8 & 60.2 & $<0.001$ \\
\hline \multicolumn{4}{|l|}{ Iodine content in the salt } \\
\hline Insufficient & 42.6 & 57.4 & 0.057 \\
\hline \multicolumn{4}{|l|}{ Biological and health-related variables } \\
\hline \multicolumn{4}{|l|}{ Sex } \\
\hline Feminine & 40.6 & 59.4 & 0.014 \\
\hline \multicolumn{4}{|l|}{ Age group } \\
\hline 6 to 12 years & 40.2 & 59.8 & $<0.001$ \\
\hline \multicolumn{4}{|l|}{ Prenatal } \\
\hline No & 48.1 & 51.9 & $<0.001$ \\
\hline \multicolumn{4}{|l|}{ Environmental variables } \\
\hline \multicolumn{4}{|l|}{ Origin of drinking water } \\
\hline Shallow well, river, well pit or dam & 45.6 & 54.4 & $<0.001$ \\
\hline \multicolumn{4}{|l|}{ Destination of domestic sewage } \\
\hline Near the residence or open sewer & 42.4 & 57.6 & $<0.001$ \\
\hline \multicolumn{4}{|l|}{ Destination of trash } \\
\hline Thrown in the forest, yard or dump & 50.5 & 49.5 & $<0.001$ \\
\hline \multicolumn{4}{|l|}{ Socio-economic variables } \\
\hline \multicolumn{4}{|l|}{ Location of the residence } \\
\hline Rural & 44.1 & 55.9 & $<0.001$ \\
\hline \multicolumn{4}{|l|}{ Mother's level of schooling } \\
\hline Up to 4 years & 41.4 & 58.6 & $<0.001$ \\
\hline \multicolumn{4}{|l|}{ Family income } \\
\hline$\leq 1 / 2$ monthly minimum wage & 38.7 & 61.3 & $<0.001$ \\
\hline \multicolumn{4}{|l|}{ Expenditures on food } \\
\hline$>50 \%$ of family income & 42.7 & 57.3 & $<0.001$ \\
\hline \multicolumn{4}{|l|}{ Food and nutritional security situation } \\
\hline Some degree of insecurity & 41.4 & 58.6 & $<0.001$ \\
\hline
\end{tabular}

${ }^{*}$ Note: Significance level $(\alpha)=0.2$. 
Table 6. Final logistic model with the odds ratio adjusted for the variables associated with iodine deficiency among schoolchildren, Novo Cruzeiro, 2008.

\begin{tabular}{|c|c|c|c|c|c|c|}
\hline \multirow{2}{*}{ Variable } & \multirow{2}{*}{ OOR } & \multicolumn{2}{|c|}{ Confidence interval of $95 \%$} & \multirow{2}{*}{ Coefficient } & \multirow{2}{*}{ Wald $X^{2}$} & \multirow{2}{*}{$\mathbf{p}$} \\
\hline & & Lower & Upper & & & \\
\hline Constant & 0.096 & & & -2.34 & 198.04 & $<0.001$ \\
\hline $\begin{array}{c}\text { Concept of iodized salt } \\
\text { yes } \rightarrow \text { no }\end{array}$ & 2.04 & 1.65 & 2.53 & 0.713 & 42.48 & $<0.001$ \\
\hline $\begin{array}{l}\text { Iodine content in table salt } \\
\text { adequate } \rightarrow \text { insufficient }\end{array}$ & 1.27 & 1.1 & 1.52 & 0.238 & 6.54 & 0.011 \\
\hline $\begin{array}{c}\text { Age group } \\
>12 \text { years } \rightarrow 6 \text { to } 12 \text { years }\end{array}$ & 1.45 & 1.22 & 1.72 & -0.372 & 17.61 & $<0.001$ \\
\hline $\begin{array}{l}\text { Location of the residence } \\
\text { urban } \rightarrow \text { rural }\end{array}$ & 2.24 & 1.89 & 2.65 & 0.806 & 89.05 & $<0.001$ \\
\hline $\begin{array}{l}\text { Mother's level of schooling } \\
>4 \text { years } \rightarrow \text { up to } 4 \text { years }\end{array}$ & 1.25 & 1.1 & 1.43 & -0.22 & 9.33 & 0.002 \\
\hline $\begin{array}{l}\text { Food and nutritional security situation } \\
\text { secure } \rightarrow \text { insecure }\end{array}$ & 2.18 & 1.71 & 2.78 & 0.777 & 39.23 & $<0.001$ \\
\hline
\end{tabular}

Considering that the addition of iodine to salt constitutes the chosen method for the prevention of the consequences of iodine deficiency in Brazil, it is of fundamental importance that the entire population consume iodized salt and know how to store it correctly, so as to reduce the risk of iodine loss [5]. Hence, this is the first study that has sought to evaluate the quality conditioning factors for salt in relation to the iodine content.

Regarding the variables related to the storage and consumption of iodized salt that were studied, incorrect storage methods, failure to pay attention to important information on the salt packaging labels when acquiring the product and mothers' level of schooling have been shown to be strongly associated with an insufficient iodine content in the salt consumed by the family.

The greatest number of samples with an insufficient iodine content came from residences in which the iodized salt was stored in an incorrect manner.

Environmental factors such as variations in weather/climate that may interfere with the permanence of the iodine in the salt must be considered [19]. In addition, though potassium iodate is stable in its pure form, its permanence in table salt depends on external conditions such as ambient humidity, the manner in which it is stored and the storage period [5].

Thus, the way that the salt is stored after being removed from its original packaging and storage in very humid areas or near sources of heat constitute variants that contribute towards the deterioration of the quantity of iodine in the salt and, consequently, towards a reduction in the levels ingested by the population.

The failure to observe the relevant information on the salt packaging labels at the time the salt is acquired is also associated with low iodine concentrations in salt. The chance that a sample with an iodine content below that recommended will come from a residence in which the person responsible for procuring the salt does not have the habit of reading the pertinent information on the salt packaging label, such as the iodized salt certification and the expiry date, was 50\% higher. The lack of attention to the expiry date for the salt at the time it is acquired constitutes a relevant factor in the evaluation of the quality of the product, since, after the expiry date, there is no guarantee that the product will present adequate quantities of iodine and may not be appropriate for consumption. Research conducted by the Adolfo Lutz Institute investigated some of the characteristics related to the conservation and storage of table salt and revealed that two years is the maximum storage period for salt under normal environmental conditions [20].

Another variable associated with the iodine content in table salt was the mothers' level of schooling. It was noted that the chances of a sample with an iodine content considered unsatisfactory coming from a residence in which the mother had less than four years of schooling were 3.44 times greater. A similar result was observed at a national level in the National Survey on Demographics and Women's and Children's Health (2006) which revealed a greater number of negative tests in terms of the presence of iodine in samples of table salt in residences in which the mothers were illiterate [21].

Traditionally, the monitoring of endemic iodine deficiency was based exclusively on studies of the prevalence 
of goiter, which therefore underestimates the subclinical deficiency of the micronutrient [8]. However, during periods of intervention by iodine supplementation through the addition of iodine to salt, the goiter prevalence rate did not constitute a good indicator, as it reflects the history of the population's iodine nutrition and does not correspond to the current nutritional state [22].

On the other hand, the evaluation of the median concentration of urinary iodine represents a method that is highly sensitive to recent variations in the dietary ingestion of iodine [10]. It is for this reason that the analysis of the excretion of iodine is being preconized and preferred by the WHO, in place of the goiter prevalence rates, as the preferential method of monitoring the magnitude of iodine deficiency, as well as an indicator concerning the impact, on the population, of the addition of iodine to salt [9].

Of the 540 schoolchildren evaluated, iodine deficiency was observed in $38.9 \%$ of them, with $28.7 \%$ presenting a slight degree (urinary iodine $<100 \mu \mathrm{g} / \mathrm{L}$ ), $6.2 \%$ presenting a moderate degree (urinary iodine $\geq 20$ and $<50$ $\mu \mathrm{g} / \mathrm{L}$ ) and $4 \%$ presenting severe degree.

The study highlights, in relation to the findings in Ouro Preto (1998), a reduction in endemic iodine deficiency, since at that time, iodine levels below $100 \mu \mathrm{g} / \mathrm{L}$ were registered in $62.5 \%$ of the schoolchildren evaluated [8].

This trend towards a decrease in the magnitude of iodine deficiency was also observed in relation to international studies. Research conducted in Lesotho among schoolchildren from 8 to 12 years of age highlighted a median urinary iodine concentration of $26.3 \mu \mathrm{g} / \mathrm{L}$, demonstrating that iodine deficiency in that country constituted a considerable public health problem [23]. In Papua New Guinea, schoolchildren from 6 to 12 years of age manifested median urinary iodine excretion of around $48 \mu \mathrm{g} / \mathrm{L}$, signifying moderate deficiency endemicity [24].

These findings confirm the significant advances in the Americas in the quest to control and eradicate iodine deficiency as a public health problem, despite the regression observed in some countries due to a lack of program sustainability.

According to the epidemiological criteria established by the WHO, the prevalence of iodine deficiency as well as the median concentration of urinary iodine observed in Novo Cruzeiro do not characterize a public health problem, since less than $50 \%$ of the schoolchildren studied presented urinary iodine of less than $100 \mu \mathrm{g} / \mathrm{L}$, and less than $20 \%$ remained below $50 \mu \mathrm{g} / \mathrm{L}$ [10] [25].

However, the distribution of the median concentration of urinary iodine was shown to be borderline, which may be observed more clearly if a stratification by residence location is performed. The urinary iodine median values both in the urban and rural environments (158.2 and $119.2 \mu \mathrm{g} / \mathrm{L}$, respectively) emphasize retrocession in the control and monitoring of the lack of iodine when compared with the findings from the Thyromobil project (2000), the last study that evaluated iodine deficiency in the region and which registered median iodine excretion above $300 \mu \mathrm{g} / \mathrm{L}$ in the municipality of Jequitinhonha and Mirabela [7].

The finding of deficiency at both levels of gravity among a significant portion of the schoolchildren evaluated (38.9\%) is sufficient for functional adaptations to occur, such as an increase in sensitivity to TSH, in serum clearance of iodine and in thyroid absorption of iodine [26].

The results of the study suggest that, despite the advances in the control of iodine deficiency in recent years in the country, there are still regions that require surveillance and interventions on education and monitoring.

When analyzing the variables associated with the iodine nutritional state, the iodized salt concept, the iodine content in salt, age group, location of the residence, mothers' level of schooling and the food and nutritional security situation were evaluated as being those that best explain the distribution of iodine deficiency in the population studied.

It was noted that the chance is twice as high of developing iodine deficiency among schoolchildren that reside in residences in which the person responsible for caring for the child had no knowledge of the concept of iodized salt and the importance of its utilization in a healthy diet. The greater proportion of people with deficiencies in this group indicates that knowing iodized salt and being aware of the importance of the use of this product in a person's daily diet constitutes a variant that may interfere in the iodine nutritional state, increasing urinary excretion.

Regarding the iodine content in table salt, it was noted that the risk was $30 \%$ greater that a child with an iodine deficiency would receive an insufficient quantity of iodine delivered through salt. As an example we may cite the results found in Ouro Preto, where it was observed that a high proportion of iodine deficient children were consuming salt with an iodine content below that of the recommendations at that time, which established iodine levels in salt of between 40 and $60 \mathrm{mg} / \mathrm{kg}$ [8].

Similarly, Correa Filho detected, during the last national survey conducted in Brazil, that the risk was 85\% 
greater that a child with goiter would reside in an area in which the addition of iodine to salt was considered moderately or severely deficient [27].

At an international level, a prospective study conducted in Switzerland revealed that a $25 \%$ increase in the recommendations regarding the concentration of iodine in iodized salt destined for human consumption available in the country resulted in considerable improvements in the iodine nutrition of pregnant women and school age children, as measured through an analysis of urinary iodine [22].

Though the study of the association between the concentration of iodine in salt and the urinary excretion of iodine is still recent, it appears that the iodine content in table salt is an important determining factor in iodine deficiency among the population.

As for the association between the age group and the deficient excretion of urinary iodine, this was shown to be more prevalent among schoolchildren belonging to the 6- to 12-year-old age group when compared with the older schoolchildren age group (13 and 14 years old). It must be remembered that children between the ages of 6 and 12 are in a phase of accelerated growth — a condition which may determine, among this age group, greater biological vulnerability to the development of iodine deficiency. Proof of this was described in a regional study conducted in Indonesia, which revealed a significant association between deficient urinary iodine excretion and low stature for in relation to age according to the z-score (HAZ) [28].

On the other hand, urinary iodine excretion tends to increase with age [19], whereas older children and adolescents tend to present greater ingestion of iodine as a consequence of their greater food intake.

Regarding the socio-economic characteristics studied, the location of the residence, the mother's level of schooling and the food and nutritional security status were shown to be associated with iodine deficiency.

As for the mothers' level of schooling, a high proportion of iodine deficiency was observed among schoolchildren with mothers with less than four years of schooling.

The level of schooling constitutes an important social indicator, since it is related to the level of knowledge and personal cognition [29], in addition to its role in synthesizing a range of social conditions that may, indirectly, determine the occurrence of the health/disease process.

The contribution of education to the maintenance of good health among children is reinforced by many public health specialists. Candwell, when studying mothers' level of schooling as a determiner of child health conditions, suggested that education modifies women's knowledge of and their opinions on the cause, prevention and treatment of diseases, thus influencing the care taken with the health of their children, including diet [30]. Also, the association between mothers' level of schooling and the concentration of iodine in table salt observed in this study may also have interfered with the deficient excretion of urinary iodine.

Another factor associated with iodine deficiency was the family food and nutritional security status. The classification of the state of food security is obtained in a practical and quick manner using the Brazilian Nutritional Food Insecurity Scale (EBIA), developed at the department of agriculture in the United States and adapted and validated for the Brazilian reality [31]. This instrument was developed to identify, at the family level, the occurrence of food and nutritional insecurity in its different degrees (slight, moderate or severe), passing through alterations that range from the psychological plane characterized by the fear of a possible lack of food to the manifestation of hunger in virtue of an absolute lack of food [32].

Various studies have been published in Brazil correlating the food security situation with various social determiners such as income, level of education and environmental and infrastructure conditions, which may exert an influence, even if distally, health conditions and access to and consumption of food [32] [33]. However, no publications were found that have correlated food (in) security with specific forms of nutritional deficiencies.

The association between iodine deficiency and food and nutritional insecurity in its different levels of gravity, however, has not yet been made clear, but must be interpreted based on the understanding of the relationship between this and unfavorable social development indicators, such as a low per capita income, a low level of education and a poor environmental situation, thus determining worse health and nutrition conditions.

\section{Conclusions}

This study allows for the conclusion that the prevalence of iodine deficiency observed in Novo Cruzeiro does not constitute, according to the criteria established by the WHO, a public health problem. However, the marginal distribution of the median concentration of urinary iodine indicates a reduction in excretion levels in relation to those found in the previous survey in the region. 
The coverage of the iodized salt program has been shown to be not effective in this municipality.

The considerable prevalence of iodine deficiency suggests that the control actions aimed at iodine deficiency disorders being implemented in the country are not complete in all regions and must have as a goal the prophylaxis of the subtle and underestimated manifestations of low ingestion.

Also, when comparing the findings of this study with the reports from recent studies that indicate elevated urinary excretion in virtue of excessive ingestion of iodine, it is possible to suppose that the distribution of iodine deficiency in Brazil is heterogeneous and linked to social determiners that are characteristic of the region in which it is found. However, new studies are needed to improve the understanding of the nature of these associations.

It is therefore suggested that the periodical monitoring be continued utilizing the excretion of urinary iodine and the iodine content in household salt as parameters for the evaluation of the iodine nutritional state of the population and, based on this data, that the areas at risk of deficiency be identified and adequate control and prevention measures be adopted.

\section{Acknowledgements}

This work was financed by the Foundation for Promotion Research of Minas Gerais (FAPEMIG), in the form of a master's degree scholarship granted to Mariana de Souza Macedo, and by the National Scientific and Technological Development Council (CNPq), by means of financial assistance, which made it possible to undertake the research. We would also like to thank the City Hall, Health Department and Education Department of the municipality of Novo Cruzeiro for their support during the data collection.

\section{References}

[1] (2007) International Council for the Control of Iodine Deficiency Disorders. www.iccidd.org

[2] Lamberg, B.A. (1993) Iodine Deficiency Disorders and Endemic Goiter. European Journal of Clinical Nutrition, 47, $1-8$.

[3] Hetzel, B.S. (1989) The Story of Iodine Deficiency: An International Challenge in Nutrition. Oxford University Press, Oxford.

[4] WHO/UNICEF/ICCIDD (2008) Assessment of Iodine Deficiency Disorders and Monitoring Their Elimination: A Guide for Programme Managers. 3rd Edition.

[5] (2007) Cadernos de Atenção Básica n. 20. Carências de micronutrientes. Ministério da Saúde, Brasília, Cadernos de Atenção Básica, 60 p.

[6] Corrêa Filho, H.R., Vieira, J.B.F., Silva, Y.S.P., Coelho, E., Cavalcante, F.A.C. and Pereira, M.P.L. (2002) Inquérito sobre a prevalência de bócio endêmico no Brasil em escolares de 6 a 14 anos: 1994 a 1996. Pan American Journal of Public Health, 12, 317-326. http://dx.doi.org/10.1590/S1020-49892002001100005

[7] Pretell, E.A. (2002) Thyromobil Project in Latin América: Reporto of the Study in Brazil. Relatório apresentado ao Ministério da Saúde. Brasília, DF, 2000. In: Organização Pan-Americana de Saúde. Organização Mundial de Saúde. Bibliografia sobre deficiência de micronutrientes no Brasil 1990-2000. Iodo e Bócio endêmico, Brasília, 40 p.

[8] Nimer, M., Silva, M.E. and Oliveira, J.E.D. (2002) Associações entre iodo no sal e iodúria em escolares, Ouro Preto, MG. Revista de Saúde Pública, 36, 500-504. http://dx.doi.org/10.1590/S0034-89102002000400017

[9] World Health Organization (1994) Indicators for Assessing Iodine Deficiency Disorders and Their Control through Salt Iodization. Micronutrient Series. Document. WHO, Geneva, 55 p.

[10] World Health Organization, United Nations Children's Fund, International Council for Control of the Iodine Deficiency Disorders (2001) Assessment of Iodine Deficiency Disorders and Monitoring Their Elimination. A Guide for Program Managers. World Health Organization, Geneva.

[11] Silva, C.A.M. (2007) Estado nutricional, consumo alimentar, hipovitaminose A, anemia e resposta de fase aguda entre menores de seis a 71 meses em Berilo, Vale do Jequitinhonha, MG. Tese (Doutorado em Parasitologia), Universidade Federal de Minas Gerais, Belo Horizonte.

[12] Anvisa (2003) Resolução RDC n 130. Diário Oficial da União.

[13] Sandell, E.B. and Kolthoff, I.M. (1937) Micro Determination of Iodine by a Catalytic Method. Microchimica Acta, 1, 9-25. http://dx.doi.org/10.1007/BF01476194

[14] Esteves, R.Z., Kasamatsu, T.S., Kunii, I.S., Furukawa, G.K., Vieira, J.G.H. and Maciel, R.M.B. (2007) Desenvolvimento de um Método para determinação da iodúria e sua aplicação na excreção urinária de iodo em escolares 
brasileiros. Arquivos Brasileiros de Endocrinologia e Metabologia, 51, 1477-1484. http://dx.doi.org/10.1590/S0004-27302007000900010

[15] Dunn, J.T., Crutchfield, H.E., Gutekunst, R. and Dunn, A.D. (1993) Two Simple Methods for Measuring Iodine in Urine. Thyroid, 3, 119-123. http://dx.doi.org/10.1089/thy.1993.3.119

[16] World Health Organization (2004) Recommended Iodine Levels in Salt and Guidelines for Monitoring Their Adequacy and Effectiveness. 5th Report on World Nutrition, WHO, March.

[17] United Nations Children’s Fund (UNICEF) (1995) Monitoring Universal Salt Iodization Programs. UNICEF, 101 p.

[18] Brasil Ministério da Saúde (1996) Manual de combate aos distúrbios por deficiência de iodo no Brasil. Ministério da Saúde, Brasília, 34 p.

[19] Duarte, G.C. (2007) Avaliação ultrassonográfica da tireoide, excreção urinária de iodo em escolares de 6 a 14 anos e grau de iodação do sal em diferentes regiões do estado de São Paulo. Tese de doutorado, Universidade de São Paulo, São Paulo.

[20] Silveira, N.V., Rodas, M.A., Saruwtari, J.H. and de Souza, A. (1993) Estabilidade do teor de iodo no sal após tempo de prateleira e cocção. Revista Instituto Adolfo Lutz, 52, 41-45.

[21] Brasil Ministério da Saúde (2009) Centro Brasileiro de Análise e Planejamento. Pesquisa Nacional de Demografia e Saúde da Criança e da Mulher. 2006. Dimensões do Processo Reprodutivo e da Saúde da Criança, Brasília, 302 p.

[22] Zimmerman, M.B. (2004) Assessing Iodine Status and Monitoring Progress of Iodized Salt Programs. The Journal of Nutrition, 134, 1673-1677.

[23] Sebotsa, M.L.D., Dannhauser, A., Jooste, P.L. and Joubert, G. (2003) Prevalence of Goiter and Urinary Iodine Status of Primary-School Children in Lesotho. Bulletin of the World Health Organization, 81, 28-34.

[24] Temple, V., Mapira, P., Adeniyi, K. and Sims, P. (2004) Iodine Deficiency in Papua New Guinea (Sub-Clinical Iodine Deficiency and Salt Iodization in the Highlands of the Papua New Guinea). Journal of Public Health, 27, 45-48. http://dx.doi.org/10.1093/pubmed/fdh199

[25] Delange, F., Benoist, B. and Burgi, H. (2002) Determining Median Urinary Iodine Concentration That Indicates Adequate Iodine Intake at Population Level. Bulletin of the World Health Organization, 80, 633-636.

[26] Dumont, J.E., Ermans, A.M., Maenhaut, C., Coppée, F. and Stanbury, J.B. (1995) Large Goiter as a Maladaptation to Iodine Deficiency. Clinical Endocrinology, 43, 1-10. http://dx.doi.org/10.1111/j.1365-2265.1995.tb01886.x

[27] Filho, H.R.C. (2002) Inquérito brasileiro sobre a prevalência nacional do bócio endêmico. Relatório apresentado ao UNICEF e Ministério da Saúde. Brasília, DF, 1997. Organização Pan-americana de Saúde. Organização Mundial de Saúde. Bibliografia sobre deficiência de micronutrientes no Brasil 1990-2000. Iodo e bócio endêmico, Brasília, 40 p.

[28] Pardede, L.V.H., Hardjowasito, W., Gross, R., Dilon, D.H.S., Totoprajogo, O.S., Yosoprawoto, M., Waskito, L. and Untoro, J. (1998) Urinary Iodine Excretion Is the Most Appropriate Outcome Indicator for Iodine Deficiency at Field Conditions at District Level. The Journal of Nutrition, 128, 1122-1126.

[29] Andrade, C.L.T., Szwarcwald, C.L., Gama, S.G.N. and Leal, M.C. (2004) Desigualdades socioeconômicas do baixo peso ao nascer e da mortalidade perinatal no município do Rio de Janeiro, 2001. Caderno de Saúde Pública, 20, S44S51.

[30] Cadwell, J. (1979) Education as a Factor in Mortality Decline: An Examination of Nigerian Data. Population Studies, 33, 395-413. http://dx.doi.org/10.2307/2173888

[31] Bickel, G., Nord, M., Price, C., Hamilton, W. and Cook, J. (2000) Guide to Measuring Household Food Security: Revised 2000. United States Department of Agriculture, Food and Nutrition Service, Alexandria.

[32] Panigassi, G., Segal-Corrêa, A.M., Marin-Léon, L., Perez-Escamilla, R., Sampaio, M.F.A. and Maranha, L.K. (2008) Insegurança alimentar como indicador de iniquidade: Análise de inquérito populacional. Caderno de Saúde Pública, 24, 2376-2384. http://dx.doi.org/10.1590/S0102-311X2008001000018

[33] Salles-Costa, R., Pereira, R.A., Vasconsellos, M.T.L., Veiga, G.V., Marins, V.M.R., Jardim, B.C., Gomes, F.S. and Sichiery, R. (2008) Associação entre fatores socioeconômicos e segurança alimentar: Estudo de base populacional na região metropolitana do Rio de Janeiro, Brasil. Revista de Nutrição, 21, 99s-109s. 
Scientific Research Publishing (SCIRP) is one of the largest Open Access journal publishers. It is currently publishing more than 200 open access, online, peer-reviewed journals covering a wide range of academic disciplines. SCIRP serves the worldwide academic communities and contributes to the progress and application of science with its publication.

Other selected journals from SCIRP are listed as below. Submit your manuscript to us via either submit@scirp.org or Online Submission Portal.
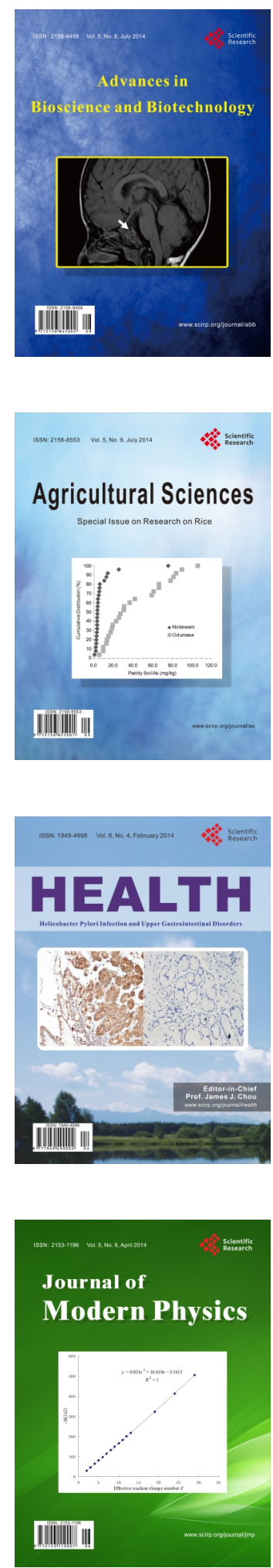
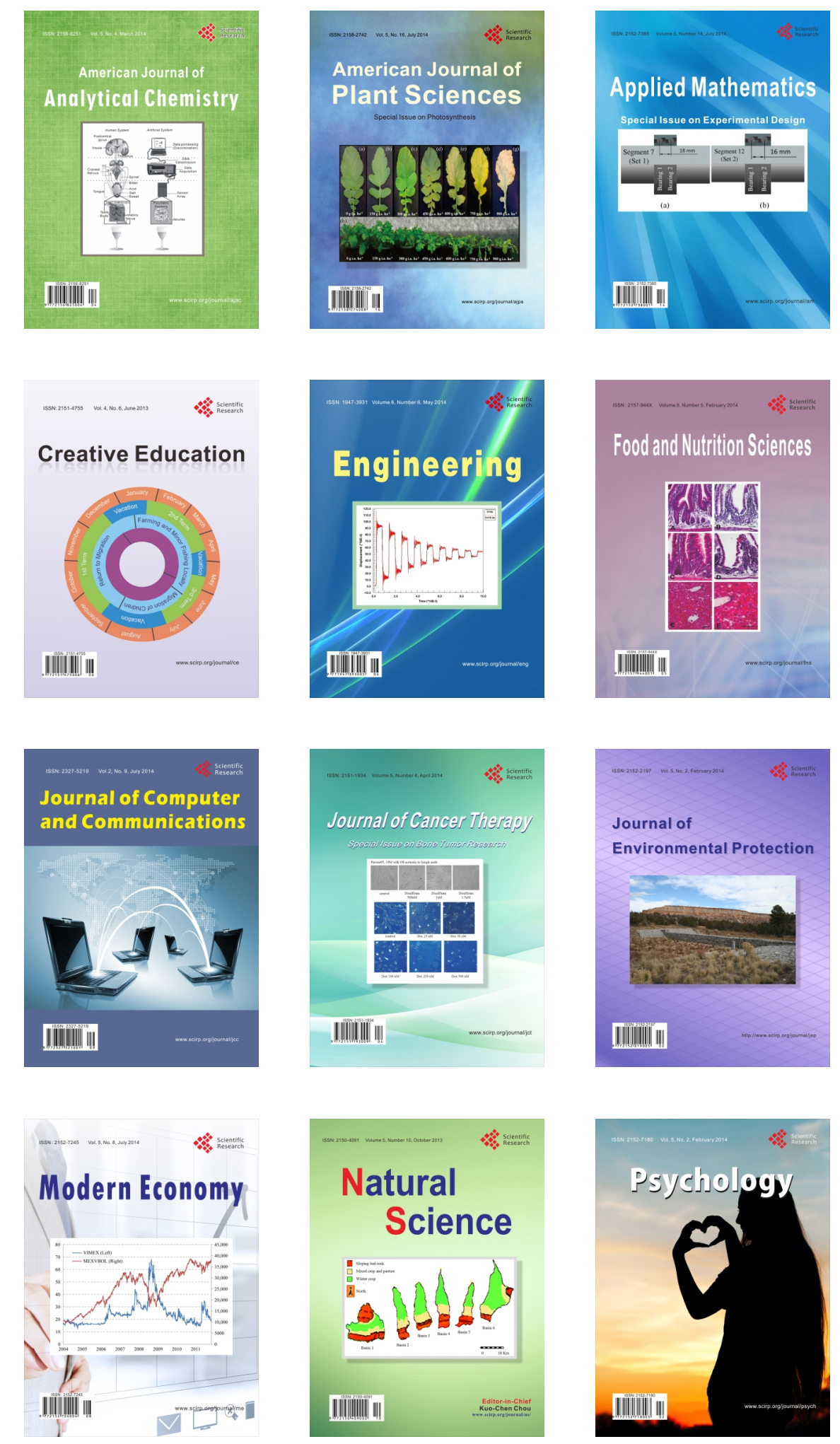